\title{
Cancer diagnostics: The journey from histomorphology to molecular profiling
}

\author{
Atif A. Ahmed ${ }^{1}$ and Malak Abedalthagafi ${ }^{2,3}$ \\ ${ }^{1}$ Department of Pathology and Laboratory Medicine, Children's Mercy Hospital, Kansas City, Missouri, USA \\ 2 Brigham and Women's Hospital, Harvard Medical School, Boston, MA, USA \\ ${ }^{3}$ The Saudi Human Genome Laboratory, Department of Pathology, King Fahad Medical City, King Abdulaziz City for Science \\ and Technology, Riyadh, Saudi Arabia
}

Correspondence to: Atif A. Ahmed, email: aahmed@cmh.edu

Keywords: cancer diagnosis, histomorphology, targeted therapy, targeted molecular profile

Received: May 10, $2016 \quad$ Accepted: July 19, $2016 \quad$ Published: August 04, 2016

\section{ABSTRACT}

\begin{abstract}
Although histomorphology has made significant advances into the understanding of cancer etiology, classification and pathogenesis, it is sometimes complicated by morphologic ambiguities, and other shortcomings that necessitate the development of ancillary tests to complement its diagnostic value. A new approach to cancer patient management consists of targeting specific molecules or gene mutations in the cancer genome by inhibitory therapy. Molecular diagnostic tests and genomic profiling methods are increasingly being developed to identify tumor targeted molecular profile that is the basis of targeted therapy. Novel targeted therapy has revolutionized the treatment of gastrointestinal stromal tumor, renal cell carcinoma and other cancers that were previously difficult to treat with standard chemotherapy. In this review, we discuss the role of histomorphology in cancer diagnosis and management and the rising role of molecular profiling in targeted therapy. Molecular profiling in certain diagnostic and therapeutic difficulties may provide a practical and useful complement to histomorphology and opens new avenues for targeted therapy and alternative methods of cancer patient management.
\end{abstract}

\section{INTRODUCTION}

The management of patients with cancer has always been a challenge to those working in the healthcare field. Despite significant research and practical advances that were made over the past few decades, the war against cancer is far from being over. Classic approaches to cancer treatment include a combination of surgery, radiotherapy, chemotherapy and hormonal therapy. With modern techniques and therapeutic options, the mortality and morbidity from cancer have decreased significantly in the past two decades. However, problems of therapy resistance and tumor progression and recurrence still plague many cancer survivors. The current treatment approach is based on a diagnosis of cancer that is rendered after pathologic analysis of the tumor and its characteristics. The process of histopathologic visualization of tumor cells, herein referred to as histomorphology, is the cornerstone of the pathologist labeling of a tumor as carcinoma, sarcoma or melanoma and is the basis of cancer treatment Advances in histopathology, which were largely fueled by curiosity regarding tumor morphology, have led to the development of an array of pathologic nomenclatures and classifications of different tumors.

In the past few decades, numerous research discoveries have been made in identifying genetic aberrations that have resulted in better understanding of the pathogenesis of malignancies and have allowed for more refined tumor diagnosis. The demonstration of specific genes mutations, fusion transcripts and chromosomal translocations has been of pivotal importance in the diagnosis of numerous cancers particularly sarcomas, some other solid tumors, lymphomas and leukemias. Genetic events in tumors result in the over-expression of signaling transduction pathways that regulate tumor proliferation, growth and spread. The link between genetic aberrancies and activation of signaling pathways and the mapping of different growth factors and their receptors have been elucidated in many tumors. These advances have allowed for more accurate diagnosis as well as 
exploration of novel therapeutics that target these genetic events and signaling pathways. The research on targeted therapy was sparked by discovery of imatinib mesylate and its broad anti-tumor effects $[1,2]$. This tyrosine-inhibitory compound has been successful in targeting KIT mutations and related genetic aberrations in gastrointestinal stromal tumor (GIST), chronic myeloid leukemia and other c-kit expressing tumors. In many instances, the presence of KIT mutations in a tumor is equivalent to responsiveness to imatinib mesylate. Targeting KIT or other tyrosine kinase receptors has been at the epicenter of this exponential genomic research, and has opened new avenues in cancer classification and management.

\section{ROLE OF TUMOR HISTOMORPHOLOGY}

Histomorphology is an ancient technique that has been essential in the identification and the diagnosis of all types of benign and malignant tumors. A portion of the patient's tumor tissue is fixed for several hours and subjected to histological processing technique that includes paraffin-embedding, microtome-sectioning and staining with hematoxylin and eosin stains that pathologists have been using for over a century [3, 4]. The stained sections are then microscopically reviewed by the pathologist who will draw upon his/her training and expertise to determine the nature and characteristics of the tumor. The basic triad of "histology, microscopy and the pathologist examination" results in a relatively short and inexpensive process. Currently, the cost of a single H\&E slide averages \$18 and most hospitals charge \$10-45 per slide [5]. Financial expenses are mainly encountered in the initial laboratory set-up and training and salaries of pathologists and histotechnologists. The time period from obtaining a tumor specimen to the final pathologic diagnosis is 24 hours in urgent settings and is commonly 3 days in standard protocols.

Histomorphology has been valuable in the assessment of tumor topography and cellular morphology and in the classification and nomenclature of variety of disease entities. It also adds value to patients' management by identifying certain prognostic indicators such as lymphovascular invasion, infiltration of adjacent organs, necrosis, and mitotic rate. However, since the invention of light microscope in the sixteenth century and the discovery of hematoxylin and eosin stains more than a century ago, the process of histomorphology has remained as such without much change [3, 4, 6, 7]. Few but important advances in the field have been made, such as in the development of immunohistochemistry, in situ hybridization and digital pathology, all of which still rely on histomorphology and have added extra costs to patient's care $[8,9]$. Furthermore, this classic approach to the cancer diagnostic management is sometimes unsatisfactory and has been criticized for various scientific and clinical reasons:
1. Cancer diagnosis often requires ancillary tests, such as immunohistochemistry and flow cytometry. These tests are performed in independent laboratory settings that incur additional costs. Immunostained slides and special stains typically cost the patient approximately $\$ 50$ per single slide for in-house tests and an average of $\$ 200$ per send-out test [5]. The number of slides processed in diagnostic biopsies, immunohistochemical studies, and subsequent resection specimens vary from few slides to more than 20 with an average of 10 slides per case, i.e. an average total cost of $\$ 2000$ that also varies according to the cancer type [5]. Diagnostic immunohistochemical panels have been steadily increasing making it impractical for most hospitals to acquire all the inventory. These ancillary tests may delay the final diagnosis for additional few days, and the prolonged turnaround time in most hospital pathology laboratories has delayed treatment and resulted in unnecessary prolonged hospital bed stays.

2 . There is no clear and direct scientific relationship existing between the tumor morphology and the response to therapy. The current classification of tumors vastly depends on histomorphology which has hampered any novel attempt to reclassify disease process or substantially develop new avenues in patient's management. Classifying malignancies into benign and malignant is sometimes ambiguated by the concepts of intermediate tumors, low grade malignancies, very low risk cancers and other tumors of variable clinical behaviors.

3. Some pathologists and treating physicians regard cancers as discrete morphologic entities whereas, in reality, cancer is a continuous disease process. Attesting to the latter fact, are the recent classifications of new diagnostic entities with intermediate morphological features that fall between two classic entities, such as ganglioneuroblastoma, B-cell lymphoma with features intermediate between diffuse large B-cell lymphoma and Burkitt lymphoma, B-cell lymphoma with features intermediate between diffuse large B-cell lymphoma and classical Hodgkin lymphoma, and transitional liver tumors that resemble hepatoblastoma and hepatocellular carcinoma [10-13]. Examples abound in the literature of tumors that have intermediate features or have a classic morphology with an "add-on" differentiation towards another morphology. Despite their apparently discrete morphology and immunophenotype, the fact that these tumors fall within a single pathway of carcinogenesis cannot be refuted.

4. Cancer histomorphology has become increasingly complex. Over the past few decades, the complexity of pathologic classification of cancers and the more vivid description of histomorphologic variants have substantially increased, fueled in part by the accumulation of rare consultation cases. Good examples include papillary thyroid carcinoma that has 12 variants, meningioma with 15 morphologic variants, and invasive breast carcinoma which has 20 described morphologic subtypes [14]. The 
subclassification of these variants is purely descriptive in most cases and does not affect the patient's prognosis or treatment. Furthermore, numerous tumors are encountered in daily practice whose nature has baffled pathologists and have since been labeled "undifferentiated sarcoma" or "undifferentiated carcinoma" (Figure 1).

5. Interpretation of histopathologic specimens can be subjective. A variable degree of discordance exists among pathologists in the interpretation of specimens depending on the specimen type and the expertise of the pathologist. A recent study published in the Journal of American Medical Association (JAMA) has reflected on the high degree of disagreement among breast pathologists and on the fact that their diagnosis may exhibit an interobserver variability in up to $25 \%$ of cases [15]. The appreciation of the subjective nature of such interpretation and the alarming degree of pathologists' discordance have led to decreased clinician confidence, increased duration and complexity of pathologists training and eventually to the increased use of diagnostic tests for which the patient will ultimately bear the costs.

\section{IMPACT OF MOLECULAR TESTING}

Molecular cancer studies have expanded beyond understanding tumor pathogenesis to the clinical laboratory setting where tests are occasionally requested to assist in the diagnosis of various tumors and aid in the patient's management. The identification of specific genetic events in tumors has fueled the development and rapid growth of molecular diagnostic tests that are based on polymerase chain reactions, immunohistochemistry or other simple techniques. The identification of $E W S / F L I 1$ chromosomal translocation and KIT/PDGFR mutations are indispensable in confirming the diagnosis of Ewing's sarcoma and GIST respectively. Furthermore, molecular tests often provide valuable information about the patient's prognosis and expected survival outcome. Combination of molecular and immunohistochemical tests has resulted in the molecular subclassification of medulloblastoma and breast cancer [16]. The identification of FLT3 mutations in acute myeloid leukemia, exon 11 mutations in GIST tumors and alpha thalassemia $\mathrm{x}$-linked protein (ATRX) and
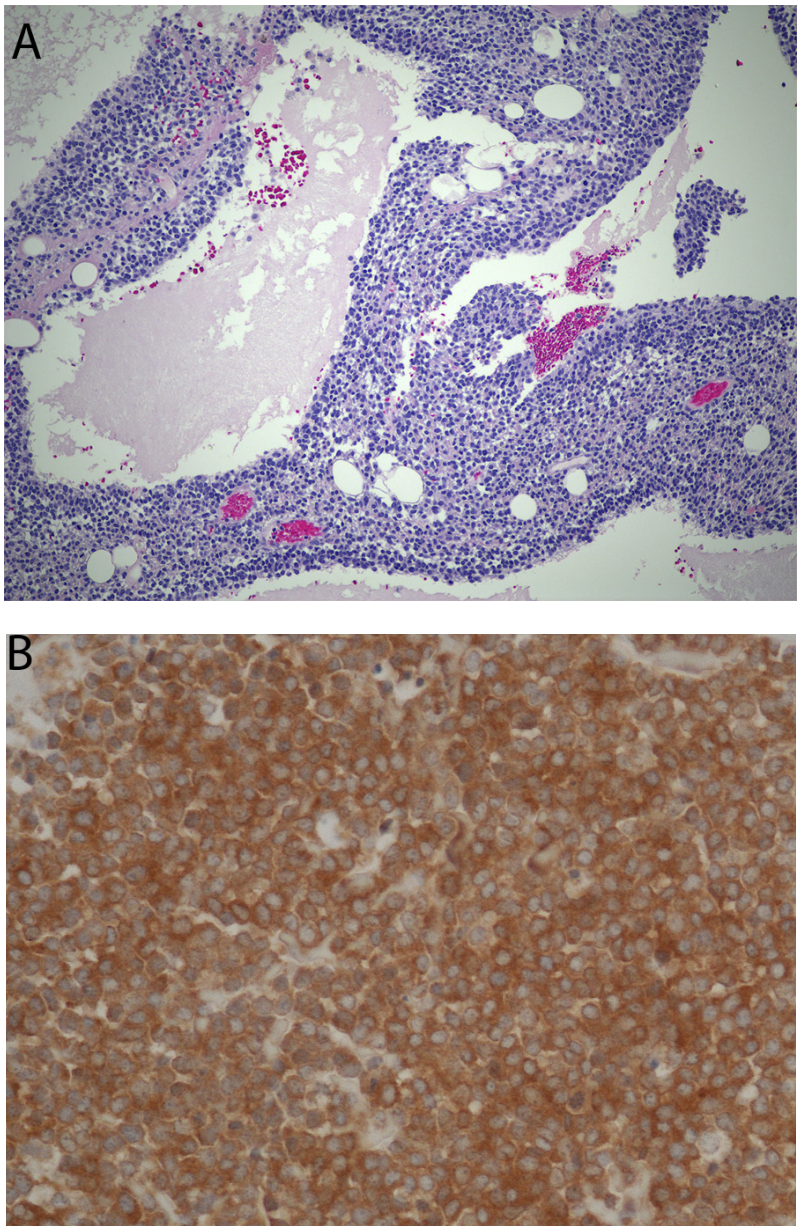

Figure 1: Histomorphologic appearance of a retroperitoneal tumor that could not be accurately classified by pathologists despite extensive work-up and opinions of multiple nationally-recognized experts (A. H\&E, x100). The tumor responded to treatment with temsirolimus and an immunohistochemical stain revealed immunoreactivity with phosphorylated mTOR antibody test (B. x200). 
Table 1: Classification of common cancers based on their molecular profile:

A. Examples of characteristic genetic and cytogenetic events:

\begin{tabular}{|l|l|}
\hline Kit Mutations & GIST, Seminoma, Adult mastocytoma, Acute myeloid leukemia, Sinonasal NK cell lymphoma \\
\hline BRAF mutations & Thyroid cancer, Melanoma, Colorectal carcinoma, Hairy cell leukemia, Brain gliomas \\
\hline ALK rearrangements & $\begin{array}{l}\text { Anaplastic T-cell lymphoma, Diffuse large B-cell lymphoma, Lung adenocarcinoma, Familial } \\
\text { neuroblastoma, Inflammatory myofibroblastic tumor, Epithelioid inflammatory myofibroblastic } \\
\text { tumor, Spitz tumor, systemic histiocytosis, Renal cell carcinoma }\end{array}$ \\
\hline EWS rearrangements & $\begin{array}{l}\text { Ewing's sarcoma family, Desmoplastic round cell sarcoma, Extraskeletal myxoid } \\
\text { chondrosarcoma, Myoepithelial tumors, Clear cell sarcoma, Angiomatoid fibrous histiocytoma, } \\
\text { Myxoid liposarcoma }\end{array}$ \\
\hline $\begin{array}{l}\text { BAF-deficient } \\
\text { dysregulated tumors }\end{array}$ & $\begin{array}{l}\text { Malignant renal and extrarenal rhabdoid tumors, Atypical rhabdoid teratoid tumor, Epithelioid } \\
\text { sarcoma, Epithelioid malignant peripheral sheath tumor, Schwannoma, Renal medullary } \\
\text { carcinoma, Sinonasal carcinoma, Vulvar carcinoma, Thoracic carcinoma, Small cell carcinoma } \\
\text { of the ovary hypercalcemic type, Synovial carcinoma, Endometrial dedifferentiated carcinoma, } \\
\text { Poorly differentiated lung carcinoma }\end{array}$ \\
\hline ATRX mutations & Brain gliomas, neuroendocrine tumors, Osteosarcoma, Liver angiosarcoma, Leiomyosarcoma \\
\hline
\end{tabular}

B. Examples of common signaling transduction pathways over-expressed in various cancers:

\begin{tabular}{|l|l|}
\hline EGFR & Lung carcinoma, Breast carcinoma, Head and neck carcinoma, Colon cancer \\
\hline IGFR & Breast cancer, Ewing's sarcoma, Rhabdomyosarcoma, Fibrosarcoma, GIST \\
\hline mTOR & Renal cell carcinoma, Breast carcinoma, Sarcomas, Medulloblastoma, Glioblastoma \\
\hline MAP/PI3k/Akt & Breast carcinoma, Endometrial cancer, Sarcomas \\
\hline VEGF & $\begin{array}{l}\text { Lung carcinoma, Colorectal carcinoma, Gynecologic cervical, Ovarian or fallopian tube } \\
\text { carcinomas }\end{array}$ \\
\hline Wnt & Colorectal carcinoma, Desmoids, Breast carcinoma, Brain tumors \\
\hline Sonic Hedgehog & $\begin{array}{l}\text { Pancreatic carcinoma, Basal cell carcinoma, Colorectal carcinoma, Metastatic prostate } \\
\text { carcinoma, Medulloblastoma }\end{array}$ \\
\hline Hippo & Osteosarcoma, Rhabdomyosarcoma, Liver cancer, Medulloblastoma \\
\hline PDL1 & $\begin{array}{l}\text { Non-small lung cancer, Breast cancer, Hodgkin's lymphoma, B-cell lymphomas, Renal cell } \\
\text { carcinoma, Gastrointestinal malignancies }\end{array}$ \\
\hline
\end{tabular}

isocitrate dehydrogenase expression in brain gliomas is clinically useful to identify aggressive cancers of different prognosis and help guide appropriate chemotherapy [1719]. These diagnostic tests are designed to complement rather than replace routine tumor histomorphology and have proven their diagnostic value in most hospitals. However, expensive molecular tests and detailed immunohistochemical panels are not widely available, thus reflecting an economic disadvantage to their use in small hospitals [20]. Notwithstanding, molecular diagnostic tests are increasingly being developed and utilized as diagnostic as well as therapeutic tests.

\section{RECLASSIFICATION OF TUMORS}

The expansive research into cancer genetic background has led to the identification of shared genetic events in tumors with diverse histologic appearances. These findings have prompted researchers and pathologists to consider classifying these tumors according to their "genomic signature" or "genetic profile". A good example is the identification of $E W S$ gene rearrangements in Ewing's sarcoma, desmoplastic round cell sarcoma, extraskeletal myxoid chrondrosarcoma, myxoid liposarcoma, clear cell sarcoma and several other cancers [21]. Similarly, KIT mutations and KIT protein expression has been identified in numerous tumors including GIST and other tumors unrelated to GIST [22]. Such tumors become amenable to inhibition by imatinib mesylate and other tyrosine kinase inhibitors. SMAR $C B 1$ (INI-1) deletions are increasingly being identified in multiple tumors [23]. Thus, the grouping of these tumors according to their shared characteristic genetic events is a justifiable approach in attempting to understand their molecular carcinogenesis and has prompted alternate classification of tumors based on their genetic profile, e.g. $A L K$-rearranged, KIT-mutated, EWS-rearranged, and INI-I deleted. Similarly, the identification of translocations and shared gene signatures has provided for the reclassification of rhabdomyosarcomas (RMS) into fusion-positive RMS and fusion negative-RMS, which includes embryonal RMS and fusion negative alveolar RMS [24]. Table 1 demonstrates a novel method of classifying cancers according to the characteristic genetic mutations and signaling profiles they express.

An interesting observation is that some genetic mutations are identified among tumors of various biologic behaviors including benign tumors, low grade and high grade malignancies. KIT mutations occur in benign entities such as mastocytosis as well as malignant tumors such as GIST. These tumors are treated differently regardless of the underlying genetic events. In these instances, 
identifying molecular events, without histomorphology, cannot predict the tumor's biologic behavior.

\section{TARGETED THERAPY}

Targeted therapy is based on the inhibition of upregulated mutational events and signaling pathways in cancers. Numerous cell growth factors and their receptors converge on the PI3K/Akt/mTor pathway and other intracellular pathways, which are widely activated in numerous cancers [25]. Preclinical and clinical studies have focused on targeting these mutated genes, growth factor receptors and intracellular signal transduction pathways over-expressed by the tumor cells [26]. Good examples include the use of mTor inhibitors in renal cell carcinomas, epidermal growth factor receptor (EGFR) and PDL1 inhibitors in non-small cell lung carcinoma and the experimental use of insulin growth factor-1 receptor (IGF1R) inhibitors in sarcomas [26].

In most cases, targeted therapy is offered to patients after the failure of routine or standard chemotherapy. Clinical trials are commonly conducted on patients previously heavily treated by conventional chemotherapy or on patients whose tumors have progressed despite adequate chemotherapy. In few instances, initial treatment with targeted therapy is offered for tumors which are considered to be resistant to conventional chemotherapy. In this regard, targeted therapy has revolutionized the treatment of renal cell carcinoma and GIST [27, 28]. The fact that many cancers share similar molecular pathways and genetic profiles makes them amenable to the same type of targeted therapy. Clinical trials of PI3K/mTor inhibitors have been conducted in variety of cancers including breast cancer, renal cell carcinomas, and hematological malignancies. Receptor tyrosine kinase inhibitors, such as imatinib, sunitinib, and dasatinib, are used to treat GIST, acute myeloid leukaemia (AML), systemic mastocytosis, meningioma, dermatofibrosarcoma protuberans, and melanoma [29].

\section{PREDICTIVE TESTS FOR PERSONALIZED TARGETED THERAPY}

Not all tumors respond to the same targeted therapy and thus predictive tests are needed to identify patients and tumors that are most likely to respond to that particular inhibitory therapy [30]. This selective step has become increasingly important with the results of clinical trials being less satisfactory than expected. Laboratory diagnostic tests to identify targetable biomarkers are currently limited but more are being developed. Few notable successes in this field include the identification of trastuzumab-responsive breast cancers by testing for Her2neu, $B C R / A B l$ translocation in chronic myeloid leukemia, and KIT mutations in imatinib-responsive GIST [31]. Additional molecularly targetable biomarker discoveries include $B R A F$ mutation testing for variable tumors like melanoma and craniopharyngioma and anaplastic lymphoma kinase (ALK) inhibitors and epidermal growth factor receptors in various subtypes of lung cancer [32, 33].

Numerous other tumors are lagging behind in the discovery and standardization of similar predictive tests. Immunohistochemical tests provide some promise as predictive tests (Figure 1) but lack the standardization and inter-observer agreements that often hurdle the development in this area [34]. King et al have summarized several ways of identifying high expression of IGF1R in tumors as predictive tests [35]. Other attempts have been made in identifying renal cell carcinomas that are responsive to mTor inhibitors and sarcomas that are responsive to IGF1R inhibitors [36, 37]. Recent advances in high throughput tumor genomic sequencing have enabled more accurate mapping of molecular phenotypes and offered potential usefulness as predictive tests for tumor responsiveness to targeted therapy [38]. The use of mouse avatar models and testing of chemotherapeutic agents in cell cultures obtained from patient's cancer has recently emerged as a novel option for selecting the most appropriate treatment plan and thus avoiding unnecessary toxicity [39]. A new role of the pathologist, particularly in pediatric hospitals, is to triage precious fresh cancer specimens in different media for variety of diagnostic tests and therapeutic uses (Figure 2).

\section{MOLECULAR PROFILING OF TUMORS}

Biologic pathways and genetic events in cancers are multiple and reveal complex interactions that affect tumor pathogenesis at different levels including initial tumorigenesis, sustained proliferation, inhibition of apoptosis, invasion and metastasis. Each tumor is expected to over-express specific genetic components or biologic pathways that are unique to the tumor, i.e. "molecular profile". However, standard genomic or molecular profiling yields massive amount of data that are non-essential and difficult to decipher and less than $20 \%$ of such data can be described as clinically relevant [40]. Only a portion of the molecular profile can be inhibited by targeted therapy and can hence be labeled as the targeted or therapeutic molecular profile (TMP). The TMP components include signal transduction pathway members, hormones, angiogenesis and apoptosis pathway members and immune system modulators. Specific genomic profiles, gene expression modulators, fusion proteins or gene mutation signatures of a tumor can be included in this profile as long as they are "actionable" or "targetable". Utilizing powerful computational methods, several web-based databases are becoming available that categorize all known protein targets including potential targets and approved drugs [41, 42]. The power of nextgeneration DNA sequencing methods in identifying 
targetable gene mutations has recently been appreciated in several studies that attempted to identify all the actionable mutations in well known cancers [43-47]. Thus, with modern technological advances and computerized software, the concept of TMP may be progressively realized and practically analyzed as more opportunities for targeted therapy are developed.

Molecular profiling has been used in large clinical centers for the targeted therapy treatment of tumors that are resistant to standard chemotherapy, progressed or metastasized despite adequate chemotherapy and in patients who do not tolerate standard chemotherapy [48]. In such instances, profiling of the metastatic tumor may be more important than the initial diagnostic specimens [49]. Complete tumor profiling at multiple platforms (e.g. gene sequencing, gene copy number and protein expression) may be performed in order to identify the proper therapeutic targets.

Molecular profiling can also offer insight into tumor classification. For example, osteosarcoma and Ewing's sarcoma and a variety of other sarcomas over-express IGF1R. Hence, these tumors can grouped together and treated with IGF1R inhibitors [50, 51]. The molecular profile or genetic signature may also be used to identify the tumor or cancer type. This concept has been recently tested by some investigators who were able to transform genomic expression data into disease diagnostic categories with $95 \%$ accuracy, a process that may alternatively be named "reverse profiling" [52]. However, until this potential is fully achieved, molecular profiling, in its current status, does not distinguish benign versus malignant tumors with high accuracy in all cases but can significantly complement tumor morphology in the overall diagnostic and therapeutic assessment of cancer.

\section{NEW WINDOW INTO CANCER PATIENT MANAGEMENT}

Resistance to treatment is a common phenomenon in treating patients with cancer and can develop de novo or during the course of treatment. The development of targeted therapy has also been confounded by resistance that extended to the use of second- or thirdgeneration molecular therapies. Although resistance to targeted therapy may be due to several pharmacologic and molecular aberrations within the tumor cells, the delay in starting such treatment until failure of previous chemotherapy may account for some of the de novo resistance mechanisms. However, an option exists for initiating targeted therapy based solely on the tumor's TMP and without prior chemotherapy. Targeted therapy is frequently considered as the last reserve in the fight against cancer and has seldom ever been tested as an initial treatment choice. Initiating treatment with targeted therapy in lieu of standard chemotherapy has been accomplished

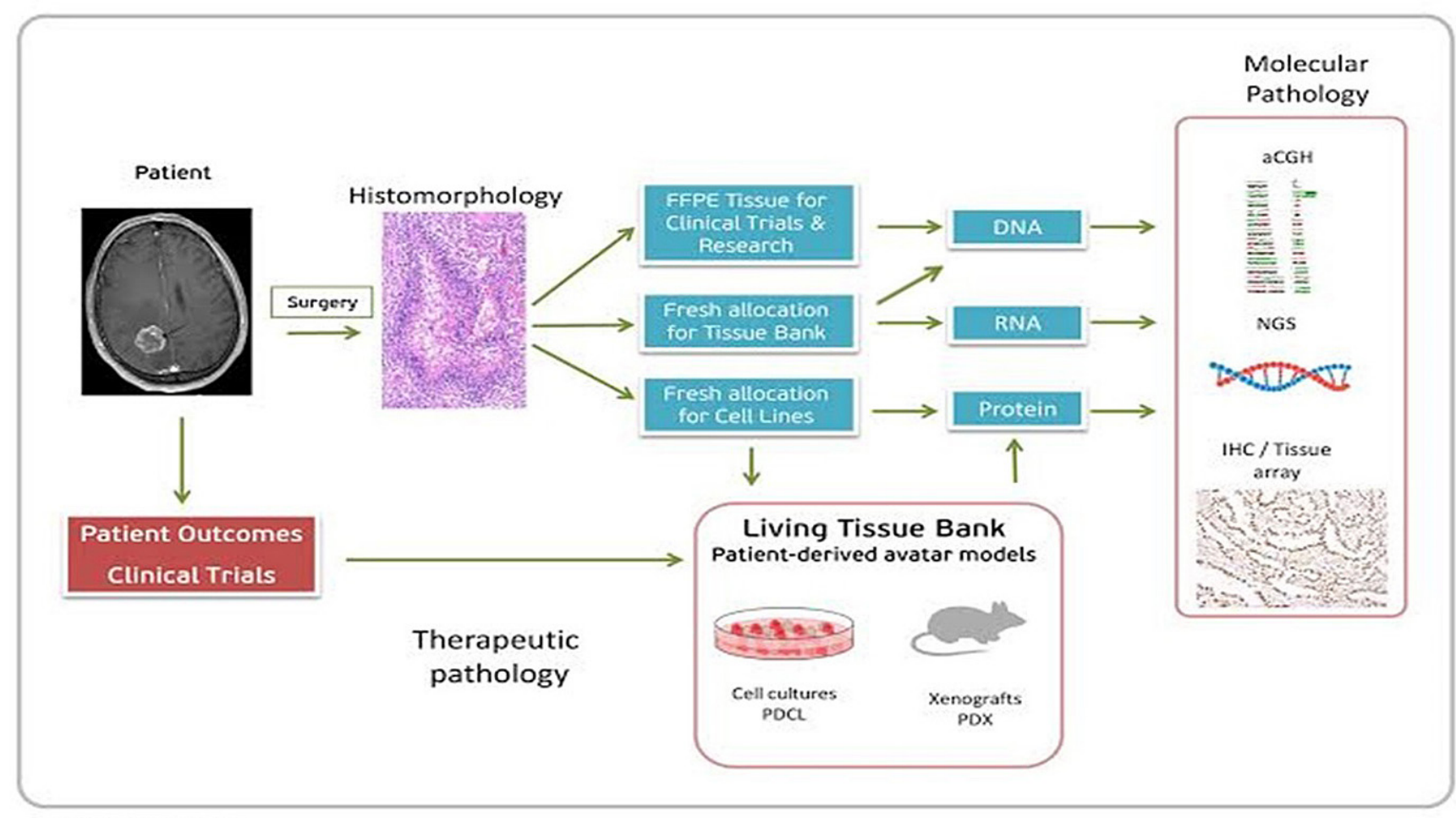

Figure 2: Triage of clinical specimens to different laboratories in the integrated approach to patient-oriented molecular and histomorphologic diagnosis for targeted real time management. 
in the treatment of gastrointestinal stromal tumors, renal cell carcinomas and few other tumors that are known to be natively resistant to standard chemotherapy [27, 28]. Following this trend, other cancers may also be treated with targeted therapy regardless of chemotherapy options.

The use of imaging technologies such as Computed Tomography and Positron Emitted Tomography has already influenced early cancer detection and management [53]. Future advances in the field of molecular imaging, integrated diagnostics, biology-driven interventional radiology and theranostics in combination with molecular profiling and targeted therapy may open a new window into patient's management potentially bypassing the need for detailed histopathologic cancer identification and standard chemotherapy [53]. In this process cancer is diagnosed through the analysis of patient symptomatology and imaging studies. The tumor is then biopsied or surgically resected. The tumor specimen is subjected to detailed molecular profiling and the most appropriate targeted therapy is offered based on the results of the tumor's TMP. Few clinical trials have addressed the possibility of targeted therapy as first-line treatment option. As a first-line treatment for advanced EGFR mutation-positive non-small cell lung carcinoma, Erlotinib was found to be superior to standard chemotherapy and conferred a better progression-free survival in patients [54]. Thus, by obviating the need for standard chemotherapy, molecular profiling and targeted therapy may provide treatment options with limited histomorphology.

\section{BENEFITS AND PITFALLS OF MOLECULAR PROFILING}

The use of molecular diagnostic tests provides a strong argument for evidence-based practice of medicine and yields a logical correlation between the molecular profile and response to targeted therapy. In combination with histomorphology, these methods can significantly complement cancer diagnosis. Non-histologic molecular diagnostic tests can be performed on the patient's tumor tissue directly or on cells harvested from body fluids and include techniques based on DNA/RNA, protein assay methods, and biologic assay methods (Figure 2). Next generation sequencing methods are leading cancer profiling research $[55,56]$, and a few advances in nonmorphologic proteomic methods have also been made [57-59]. In addition to their value in yielding diagnostic and prognostic information, molecular profiling and gene expression signatures have also been successfully used to differentiate between benign and malignant breast and thyroid lesions with high accuracy $[60,61]$.

In cancer management, the toxicity and related healthcare costs associated with the use of personalized targeted therapy are less pronounced than those of standard chemotherapy. Serious toxicities have been rarely reported, that generally reflected poor patient selection due to lack of reliable predictive tests. The selective use of cancer agents directed against a specific molecular target on cancer cells has been reported to be associated with a lower incidence of toxicity and lower healthcare costs compared with the use of less-specific targeted agents, including general angiogenesis inhibitors and chemotherapeutic agents [62]. Thus, the success of targeted therapy depends on appropriate patient selection which itself relies on the improved development of personalized predictive diagnostic tests [63]. Further development of diagnostic tests is feasible with the collaborative effort of drug manufacturers and diagnostic companies that help maintain a cost-effective approach to cancer management [12].

Conceivably, the use of molecular diagnostic tests is currently associated with the requirement for large amounts of tissue that are needed for different techniques, including precious fresh or frozen tumor tissue [64]. In contrast, cancer histomorphology can reliably be performed on small tissue samples. The ability to extract DNA from formalin-fixed paraffin-embedded tissue has encouraged many advances in the field. However, such DNA samples, particularly when used in next generation or whole exome sequencing methods, is considered to be of inferior quality and often leads to artificial sequence alterations [65, 66]. Furthermore, cancer cells exhibit genetic heterogeneity in the sense that different cancer cells from the same tumor may have different mutation types according to their maturity and genetic evolution. Such genetic variation across individual tumors, intratumoral heterogeneity, has important implication for cancer progression and has been detected at the level of circulating tumor cells [67-69]. Although the drawbacks currently limit the utilization of molecular testing, future advances may overcome these difficulties. Promising results have been reported from the use of fine needle cytology specimens and from the detection of circulating tumor cells highlighting a stronger role of molecular testing in these areas $[70,71]$.

The high cost and the lengthy turnaround time have thus far limited the widespread use of next generation sequencing platforms and their clinical applications. The price cost of DNA sequencing and microarray tests is currently fairly high [72], and varies according to the instrument and platform type. In contrast, cancer histomorphology may provide more useful information at the fraction of the cost. Furthermore, molecular sequencing is prone to errors that arise during sequencing or interpretation [73]. Comprehensive analysis requires the services of an experienced bioinformatics professional, which further increase testing costs. However through advances in targeted therapy and in certain diagnostic and therapeutic difficulties, targeted tumor profiling may ultimately result in overall direct and indirect benefits for the patients and the healthcare system and may provide considerable time and cost savings in the 
overall management of cancer patients. Technologic improvements in the future may eventually lead to cost decrease and shorter turnaround time. Recently, a rapid 26-hour whole genome sequencing method, STATseq, has enabled, in combination with the clinical phenotype, a complete molecular diagnosis of inherited genetic diseases with more than $99 \%$ sensitivity $[74,75]$. A similar method may be implemented in cancer diagnosis that allows for screening of fewer selected genes or a smaller TMP panel in combination with histomorphology with the potential for faster results.

\section{THERAPEUTIC PATHOLOGY AND INDICATIONS OF MOLECULAR PROFILING}

Given the drawbacks in cancer histomorphology and molecular profiling, there are currently no perfect methods to guide cancer treatment. However, the field of therapeutic pathology and its role in the treatment of cancer is continually evolving. Cancer histomorphology will likely continue to be the basis of cancer diagnosis and management and reconcile with the growing trend in molecular diagnosis and targeted therapy by offering a combined or integrated tumor classification scheme. A more affordable approach would be to limit molecular testing to the identification of certain therapeutic and prognostic biomarkers. In this scheme, a basic morphologic cancer diagnosis is followed by ancillary immunohistochemical or other tests that may offer prognostic or therapeutic information (Figure 2). The College of American Pathology has recently established protocols for reporting certain biomarkers in different cancers [76]. This approach can also help in further classification of certain malignancies as recently highlighted in the new World Health Organization classification of hematopoietic malignancies which has categorized new entities with integrated nomenclature such as "myeloid neoplasm with PDGFRB rearrangement", B-cell lymphoma with IRF4 rearrangement and high grade B-cell lymphoma with $M Y C$ and BCL2 and/or $B C L 6$ rearrangement [77]. While this integrated scheme offers a more comprehensive cancer assessment, it further increases the cost of cancer diagnosis and management.

Comprehensive molecular profiling based on next generation sequencing methods is currently routinely not practical but may be helpful in certain clinical situations:

1. To detect targetable mutations in otherwise difficult to treat, chemoresistant or metastatic tumors . In these cases, identifying tumor TMP from metastatic specimens is more important than tumor profiling from initial diagnostic specimens [49]. The practical use of mTOR inhibitors has been discussed in several clinical studies of metastatic renal cell carcinoma and ependymoma expressing the mutated gene or abnormal protein $[78,79]$.
2. To provide targetable options for tumors than could not be histologically adequately classified. In these situations, targeted therapy may be offered as an initial treatment option. This is particularly helpful in pediatric cancers where the robust genomic sequencing methods have helped solve the diagnostic odyssey and alleviate parents' anxiety [80-82]. Several ambitious projects in pediatric oncology programs across the USA, such as BASIC3 of Texas Children's Hospital, have suggested that clinical applications of cancer genomic testing have grown beyond the infancy stages [83-85].

3. To determine the origin of a metastatic tumor of unknown primary [86, 87]. Gene expression profile and transcriptome signature analysis were able to identify the site of origin of metastatic tumors with more than $95 \%$ accuracy $[88,89]$.

4. To provide a refined diagnosis in cases of undifferentiated malignancies. In a recent transcriptome analysis of 19 undifferentiated sarcoma of the thorax, identifying SMARCA4 mutations has placed these tumors along with malignant rhabdoid tumors rather than lung carcinomas [90].

5. To detect circulating genetic material or tumor cells in liquid biopsies from patients with metastatic disease [91];

With future advances in test costs and turnaround time, tumor profiling methods may become more affordable and practical and offer more opportunities in therapeutic pathology. There are at the present not enough data to show the life cost benefit of pure molecular profiling versus histomorphology in the management of cancer patients. However, with wider availability of molecular tests and development of successful targeted therapy, the role of cancer histomorphology may gradually decrease giving way to laboratory-based molecular tests that may be interpreted by molecular pathologists and nonMD scientific personnel.

\section{CONCLUSIONS}

The development and applications of cancer profiling methods will be the cornerstone of targeted cancer research offering novel methods of cancer classification and treatment. Comprehensive or limited cancer profiling offers an alternative approach to treat patients with difficult cancers and can supplement or supersede classical management methods such as histomorphology and chemotherapy. The success of this approach will be further appreciated through the growing research in targeted therapy and the development of accurate and less expensive molecular diagnostic tests that accurately predict the response to targeted therapy. Given the rapid pace in which advances in tumor diagnostics are expanding, pathologists, researchers and clinicians should be willing to consider novel ways of approaching cancer treatment. 


\section{Abbreviations}

ABL: Abelson murine leukemia oncogene homolog 1; AKT: protein kinase B; ALK: Anaplastic lymphoma kinase; ATRX: alpha thalassemia $\mathrm{x}$-linked protein; $\mathrm{BAF}$ : Brg/Brahma-associated factors; BCR: Breakpoint cluster region; BRAF: Murine sarcoma oncogene homolog B; EGFR: Epidermal growth factor receptor; EWS: Ewing's sarcoma oncogene; FLI1: Friend leukemia integration 1 transcription factor; FLT3: fms-like tyrosine kinase 3; H\&E: Hematoxylin and eosin; Hippo: Hippopotamus-like phenotype; GIST: Gastrointestinal stromal tumor; IGFR: Insulin growth factor receptor; INI1: Integrase interactor 1; KIT: CD117 kinase receptor; mTor: Mammalian target of rapamycin; PDGFR: Platelet-derived growth factor receptor; PDL-1: Programmed death ligand-1; PI3K: Phosphatidylinositol-3 kinase; RTK: Receptor tyrosine kinase; SMAR CB1: SWI/SNF-related matrix-associated actin-dependent regulator of chromatin subfamily B member 1; VEGF: Vascular endothelial growth factor; WNT: Wingless-type integration site

\section{ACKNOWLEDGMENTS}

We would like to thank the departments of pathology at Children's Mercy Hospital and King Fahad Medical City for the use of their resources and patients' materials

\section{CONFLICTS OF INTERESTS}

The authors declare that they have no conflict of interest.

\section{Author contributions}

All authors have contributed equally to the manuscript concept, design and writing. All authors have read and approved submission of this manuscript.

\section{REFERENCES}

1. Miettinen M. From morphological to molecular diagnosis of soft tissue tumors. Adv Exp Med Biol. 2006; 587: 99-113.

2. Hameed M. Molecular diagnosis of soft tissue neoplasia: clinical applications and recent advances. Expert Rev Mol Diagn. 2014; 14:961-77

3. King DF, King LA. A brief historical note on staining by hematoxylin and eosin. Am J Dermatopathol. 1986; 8:168.

4. Lillie RD. Histopathologic technic and practical histochemistry. 3rd edition. New York: McGraw-Hill Book Co;1965.

5. Muirhead M, Aoun P, Powell M, Juncker F, Molleru J. Pathology economic model tool: A novel approach to workflow and budget cost analysis in an anatomic pathology laboratory. Arch Pathol Lab Med. 2010; 134:1164-69.

6. Amos B. Lessons from the history of light microscopy. Nat Cell Biol. 2000; 2:E151 - E152.

7. Fischer AH, Jacobson KA, Rose J, Zeller R. Hematoxylin and eosin staining of tissue and cell sections. CSH Protoc 2008; 2008:pdb.prot4986.

8. Ho J, Ahlers SM, Stratman C, Aridor O, Pantanowitz L, Fine JL, Kuzmishin JA, Montalto MC, Parwani AV. Can digital pathology result in cost savings? A financial projection for digital pathology implementation at a large integrated health care organization. J Pathol Inform. 2014; 5:33.

9. Boyce BF. Whole slide imaging: uses and limitations for surgical pathology and teaching. Biotech Histochem. 2015; 90:321-30

10. Prokurat A, Kluge P, Kościesza A, Perek D, Kappeler A, Zimmermann A. Transitional liver cell tumors (TLCT) in older children and adolescents: a novel group of aggressive hepatic tumors expressing beta-catenin. Med Pediatr Oncol. 2002; 39:510-8.

11. Evens AM, Kanakry JA, Sehn LH, Kritharis A, Feldman T, Kroll A, Gascoyne RD, Abramson JS, Petrich AM, Hernandez-Ilizaliturri FJ, Al-Mansour Z, Adeimy C, Hemminger J, et al. Gray zone lymphoma with features intermediate between classical Hodgkin lymphoma and diffuse large B-cell lymphoma: characteristics, outcomes, and prognostication among a large multicenter cohort. Am J Hematol. 2015; 90:778-83.

12. Perry AM, Crockett D, Dave BJ, Althof P, Winkler L, Smith LM, Aoun P, Chan WC, Fu K, Greiner TC, Bierman $\mathrm{P}$, Gregory Bociek R, Vose JM, Armitage JO, Weisenburger DD. B-cell lymphoma, unclassifiable, with features intermediate between diffuse large B-cell lymphoma and burkitt lymphoma: study of 39 cases. Br J Haematol. 2013; 162:40-9.

13. Cohan JN, Moliterno JA, Mok CL, Lavi E, Boockvar JA. Pineal parenchymal tumor of intermediate differentiation with papillary features: a continuum of primary pineal tumors? J Neurooncol. 2011; 101:301-6.

14. Fletcher CDM (ed.). Diagnostic Histopathology of tumors. 4th edition. London: Churchill Livingstone; 2013.

15. Elmore JG, Longton GM, Carney PA, Geller BM, Onega T, Tosteson AN, Nelson HD, Pepe MS, Allison KH, Schnitt SJ, O’Malley FP, Weaver DL. Diagnostic concordance among pathologists interpreting breast biopsy specimens. JAMA. 2015; 313:1122-32.

16. Gupta T, Shirsat N, Jalali R. Molecular subgrouping of medulloblastoma: Impact upon research and clinical practice. Curr Pediatr Rev. 2015; 11:106-19.

17. Andersson J, Bümming $\mathrm{P}$, Meis-Kindblom JM, Sihto H, Nupponen N, Joensuu H, Odén A, Gustavsson B, Kindblom LG, Nilsson B. Gastrointestinal stromal tumors KIT exon 11 deletions are associated with poor prognosis. Gastroenterology 2006; 130:1573-81. 
18. Ozeki K, Kiyoi H, Hirose Y, Iwai M, Ninomiya M, Kodera Y, Miyawaki S, Kuriyama K, Shimazaki C, Akiyama H, Nishimura M, Motoji T, Shinagawa K, et al. Biologic and clinical significance of the FLT3 transcript level in acute myeloid leukemia. Blood 2004; 103:1901-8.

19. Abedalthagafi M, Phillips JJ, Kim GE, Mueller S, HaasKogen DA, Marshall RE, Croul SE, Santi MR, Cheng J, Zhou S, Sullivan LM, Martinez-Lage M, Judkins AR, Perry A. The alternative lengthening of telomere phenotype is significantly associated with loss of ATRX expression in high-grade pediatric and adult astrocytomas: a multiinstitutional study of 214 astrocytomas. Mod Pathol. 2013; 26: 1425-32.

20. Towse A, Ossa D, Veenstra D, Carlson J, Garrison L. Understanding the economic value of molecular diagnostic tests: case studies and lessons learned. J Pers Med. 2013; 3:288-305.

21. Fisher C. The diversity of soft tissue tumours with EWSR1 gene rearrangements: a review. Histopathology 2014; 64:134-150.

22. Went PT, Dirnhofer S, Bundi M, Mirlacher M, Schraml P, Mangialaio S, Dimitrijevic S, Kononen J, Lugli A, Simon R, Sauter G. Prevalence of KIT expression in human tumors. J Clin Oncol. 2004; 22:4514-22.

23. Hollmann TJ, Hornick JL. INI1-deficient tumors: diagnostic features and molecular genetics. Am J Surg Pathol. 2011; 35:e47-63.

24. Davicioni E, Anderson MJ, Finckenstein FG, Lynch JC, Qualman SJ, Shimada H, Schofield DE, Buckley JD, Meyer WH, Sorensen PH, Triche TJ. Molecular classification of rhabdomyosarcoma--genotypic and phenotypic determinants of diagnosis: a report from the Children's Oncology Group. Am J Pathol. 2009; 174:550-64.

25. Heinrich MC, Corless CL. Cancer: Oncogenes in context. Nature. 2010;467:796-797.

26. Lim HJ, Crowe P, Yang JL. Current clinical regulation of $\mathrm{PI} 3 \mathrm{~K} / \mathrm{PTEN} / \mathrm{Akt} / \mathrm{mTOR}$ signalling in treatment of human cancer. J Cancer Res Clin Oncol. 2015; 141:671-89.

27. Bex A, Powles T, Karam JA. Role of targeted therapy in combination with surgery in renal cell carcinoma. Int $\mathrm{J}$ Urol. 2016; 23:51-2.

28. Valsangkar N, Sehdev A, Misra S, Zimmers TA, O’Neil $\mathrm{BH}$, Koniaris LG. Current management of gastrointestinal stromal tumors: Surgery, current biomarkers, mutations, and therapy. Surgery 2015; 158: 1149-64.

29. Ashman LK, Griffith R. Therapeutic targeting of c-KIT in cancer. Expert Opin Investig Drugs. 2013; 22:103-15.

30. Tobin NP, Foukakis T, De Petris L, Bergh J. The importance of molecular markers for diagnosis and selection of targeted treatments in patients with cancer. J Intern Med. 2015; 278: 545-70.

31. Dietel M, Jöhrens K, Laffert M, Hummel M, Bläker H, Müller BM, Lehmann A, Denkert C, Heppner FL, Koch A, Sers C, Anagnostopoulos I. Predictive molecular pathology and its role in targeted cancer therapy: a review focusing on clinical relevance. Cancer Gene Ther. 2013; 20:211-21.

32. Smalley KS, Herlyn M. Targeting intracellular signaling pathways as a novel strategy in melanoma therapeutics. Ann N Y Acad Sci. 2005; 1059:16-25.

33. Kalia M. Biomarkers for personalized oncology: recent advances and future challenges. Metabolism. 2015; 64:S1621.

34. Ahmed AA. Role of pathology and immunohistochemistry in the new era of molecular therapy. The Open Conference Proceedings Journal (Bentham Open). 2010; 1:164-167.

35. King H, Aleksic T, Haluska P, Macaulay VM. Can we unlock the potential of IGF-1R inhibition in cancer therapy? Cancer Treat Rev. 2014; 40:1096-105.

36. Fiorini C, Massari F, Pedron S, Sanavio S, Ciccarese C, Porcaro AB, Artibani W, Bertoldo F, Zampini C, Sava T, Ficial M, Caliò A, Chilosi M, et al. Methods to identify molecular expression of mTOR pathway: a rationale approach to stratify patients affected by clear cell renal cell carcinoma for more likely response to $\mathrm{mTOR}$ inhibitors. Am J Cancer Res 2014; 4:907-15.

37. Schwartz GK, Tap WD, Qin LX, Livingston MB, Undevia SD, Chmielowski B, Agulnik M, Schuetze SM, Reed DR, Okuno SH, Ludwig JA, Keedy V, Rietschel P, et al. Cixutumumab and temsirolimus for patients with bone and soft-tissue sarcoma: a multicentre, open-label, phase 2 trial. Lancet Oncol. 2013; 14:371-82.

38. Wang E, Zaman N, Mcgee S, Milanese JS, Masoudi-Nejad A, O'Connor-McCourt M. Predictive genomics: a cancer hallmark network framework for predicting tumor clinical phenotypes using genome sequencing data. Semin Cancer Biol. 2015; 30:4-12.

39. Garralda E, Paz K, López-Casas PP, Jones S, Katz A, Kann LM, López-Rios F, Sarno F, Al-Shahrour F, Vasquez D, Bruckheimer E, Angiuoli SV, Calles A, et al. Integrated next-generation sequencing and avatar mouse models for personalized cancer treatment. Clin Cancer Res. 2014; 20: 2476-84.

40. Amar D, Hait T, Izraeli S, Shamir R. Integrated analysis of numerous heterogeneous gene expression profiles for detecting robust disease-specific biomarkers and proposing drug targets. Nucleic Acids Res. 2015;43: 7779-89.

41. Gao Z, Li H, Zhang H, Liu X, Kang L, Luo X, Zhu W, Chen K, Wang X, Jiang H. PDTD: a web-accessible protein database for drug target identification. BMC Bioinformatics. 2008; 9:104.

42. Liu X, Zhu F, Ma X, Tao L, Zhang J, Yang S, Wei Y, Chen YZ. The Therapeutic Target Database: an internet resource for the primary targets of approved, clinical trial and experimental drugs. Expert Opin Ther Targets. 2011; 15:903-12.

43. Cheng DT, Mitchell TN, Zehir A, Shah RH, Benayed R, Syed A, Chandramohan R, Liu ZY, Won HH, Scott SN, Brannon AR, O'Reilly C, Sadowska J, et al. Memorial 
Sloan Kettering-integrated mutation profiling of actionable cancer targets (MSK-IMPACT): A hybridization capturebased next-generation sequencing clinical assay for solid tumor molecular oncology. J Mol Diagn. 2015; 17:251-64.

44. Zhao Y, Polley EC, Li MC, Lih CJ, Palmisano A, Sims DJ, Rubinstein LV, Conley BA, Chen AP, Williams PM, Kummar S, Doroshow JH, Simon RM. GeneMed: An informatics hub for the coordination of next-generation sequencing studies that support precision oncology clinical trials. Cancer Inform. 2015; 14(Suppl 2):45-55.

45. Ananda G, Mockus S, Lundquist M, Spotlow V, Simons A, Mitchell T, Stafford G, Philip V, Stearns T, Srivastava A, Barter M, Rowe L, Malcolm J,Bult C, Karuturi RK, Rasmussen K, Hinerfeld D. Development and validation of the JAX Cancer Treatment Profile ${ }^{\mathrm{TM}}$ for detection of clinically actionable mutations in solid tumors. Exp Mol Pathol. 2015; 98:106-12.

46. Hagemann IS, Cottrell CE, Lockwood CM. Design of targeted, capture-based, next generation sequencing tests for precision cancer therapy. Cancer Genet. 2013; 206:420-31.

47. Damodaran S, Miya J, Kautto E, Zhu E, Samorodnitsky E, Datta J, Reeser JW, Roychowdhury S. Cancer Driver Log (CanDL): catalog of potentially actionable cancer mutations. J Mol Diagn. 2015; 17:554-9.

48. Tan DS, Thomas GV, Garrett MD, Banerji U, de Bono JS, Kaye SB, Workman P. Biomarker-driven early clinical trials in oncology: a paradigm shift in drug development. Cancer J. 2009; 15:406-20.

49. Cha S, Lee J, Shin JY, Kim JY, Sim SH, Keam B, Kim TM, Kim DW, Heo DS, Lee SH, Kim JI. Clinical application of genomic profiling to find druggable targets for adolescent and young adult (AYA) cancer patients with metastasis. BMC Cancer. 2016; 16:170.

50. Fleuren ED, Versleijen-Jonkers YM, van de Luijtgaarden AC, Molkenboer-Kuenen JD, Heskamp S, Roeffen MH, van Laarhoven HW, Houghton PJ, Oyen WJ, Boerman OC, van der Graaf WT. Predicting IGF-1R therapy response in bone sarcomas: immuno-SPECT imaging with radiolabeled R1507. Clin Cancer Res. 2011; 17:7693-703.

51. Huang X, Park H, Greene J, Pao J, Mulvey E, Zhou SX, Albert CM, Moy F, Sachdev D, Yee D, Rader C, Hamby CV, Loeb DM, Cairo MS, Zhou X. IGF1R- and ROR1specific CAR T cells as a potential therapy for high risk sarcomas. PLoS One 2015; 10:e0133152.

52. Huang $\mathrm{H}$, Liu CC, Zhou XJ. Bayesian approach to transforming public gene expression repositories into disease diagnosis databases. Proc Natl Acad Sci USA 2010; 107:6823-6828.

53. Mahajan A, Goh V, Basu S, Vaish R, Weeks AJ, Thakur $\mathrm{MH}$, Cook GJ. Bench to bedside molecular functional imaging in translational cancer medicine: to image or to imagine? Clin Radiol. 2015; 70:1060-82.

54. Zhou C, Wu YL, Chen G, Feng J, Liu XQ, Wang C, Zhang S, Wang J, Zhou S, Ren S, Lu S, Zhang L, Hu C, et al.
Erlotinib versus chemotherapy as first-line treatment for patients with advanced EGFR mutation-positive non-smallcell lung cancer (OPTIMAL, CTONG-0802): a multicentre, open-label, randomised, phase 3 study. Lancet Oncol. 2011; 12:735-42.

55. Guan YF, Li GR, Wang RJ, Yi YT, Yang L, Jiang D, Zhang XP, Peng Y. Application of next-generation sequencing in clinical oncology to advance personalized treatment of cancer. Chin J Cancer 2012; 31:463-70.

56. Chan $\mathrm{M}$, Lee $\mathrm{CW}, \mathrm{Wu} \mathrm{M}$. Integrating next-generation sequencing into clinical cancer diagnostics. Expert Rev Mol Diagn. 2013; 13:647-50.

57. Dias MH, Kitano ES, Zelanis A, Iwai LK. Proteomics and drug discovery in cancer. Drug Discov Today. 2016; 21:264-77.

58. Maes E, Mertens I, Valkenborg D, Pauwels P, Rolfo C, Baggerman G. Proteomics in cancer research: Are we ready for clinical practice? Crit Rev Oncol Hematol. 2015; 96:437-48.

59. Santini AC, Giovane G, Auletta A, Di Carlo A, Fiorelli A, Cito L, Astarita C, Giordano A, Alfano R, Feola A, Di Domenico M. Translational research and plasma proteomic in cancer. J Cell Biochem. 2016; 117:828-35.

60. Yang L, Cui X, Zhang N, Li M, Bai Y, Han X, Shi Y, Liu H. Comprehensive lipid profiling of plasma in patients with benign breast tumor and breast cancer reveals novel biomarkers. Anal Bioanal Chem. 2015; 407:5065-77.

61. Borrelli N, Ugolini C, Giannini R, Antonelli A, Giordano M, Sensi E, Torregrossa L, Fallahi P, Miccoli P, Basolo F. Role of gene expression profiling in defining indeterminate thyroid nodules in addition to BRAF analysis. Cancer Cytopathol. 2016; 124:340-9.

62. Niraula S, Amir E, Vera-Badillo F, Seruga B, Ocana A, Tannock IF. Risk of incremental toxicities and associated costs of new anticancer drugs: a meta-analysis. J Clin Oncol 2014; 32:3634-42.

63. Jiang Y, Wang M. Personalized medicine in oncology: tailoring the right drug to the right patient. Biomark Med. 2010; 4: 523-33.

64. Khoury JD, Catenacci DV. Next-generation companion diagnostics: promises, challenges, and solutions. Arch Pathol Lab Med. 2015; 139:11-3.

65. Wong SQ, Li J, Tan AY, Vedururu R, Pang JM, Do H, Ellul J, Doig K, Bell A, MacArthur GA, Fox SB, Thomas DM, Fellowes A, Parisot JP, Dobrovic A; CANCER 2015 Cohort. Sequence artefacts in a prospective series of formalin-fixed tumours tested for mutations in hotspot regions by massively parallel sequencing. BMC Med Genomics. 2014;7:23.

66. Oh E, Choi YL, Kwon MJ, Kim RN, Kim YJ, Song JY, Jung KS, Shin YK. Comparison of accuracy of wholeexome sequencing with formalin-fixed paraffin-embedded and fresh frozen tissue samples. PLoS One. 2015; 10:e0144162. 
67. O'Brien CP, Taylor SE, O'Leary JJ, Finn SP. Molecular testing in oncology: problems, pitfalls and progress. Lung Cancer. 2014; 83:309-15.

68. Hardiman KM, Ulintz PJ, Kuick RD, Hovelson DH, Gates CM, Bhasi A, Rodrigues Grant A, Liu J, Cani AK, Greenson JK, Tomlins SA, Fearon ER. Intra-tumor genetic heterogeneity in rectal cancer. Lab Invest. 2016; 96:4-15.

69. Salvianti F, Pazzagli M, Pinzani P. Single circulating tumor cell sequencing as an advanced tool in cancer management. Expert Rev Mol Diagn. 2016; 16:51-63.

70. Kanagal-Shamanna R, Portier BP, Singh RR, Routbort MJ, Aldape KD, Handal BA, Rahimi H, Reddy NG, Barkoh BA, Mishra BM, Paladugu AV,Manekia JH, Kalhor N, et al. Next-generation sequencing-based multi-gene mutation profiling of solid tumors using fine needle aspiration samples: promises and challenges for routine clinical diagnostics. Mod Pathol. 2014; 27:314-27.

71. Campton DE, Ramirez AB, Nordberg JJ, Drovetto N, Clein AC, Varshavskaya P, Friemel BH, Quarre S, Breman A, Dorschner M, Blau S, Blau CA, Sabath DE, et al. Highrecovery visual identification and single-cell retrieval of circulating tumor cells for genomic analysis using a dual-technology platform integrated with automated immunofluorescence staining. BMC Cancer. 2015; 15:360.

72. Gallego CJ, Shirts BH, Bennette CS, Guzauskas G, Amendola LM, Horike-Pyne M, Hisama FM, Pritchard CC, Grady WM, Burke W, Jarvik GP, Veenstra DL. Nextgeneration sequencing panels for the diagnosis of colorectal cancer and polyposis syndromes: A cost-effectiveness analysis. J Clin Oncol. 2015; 33:2084-91.

73. Nguyen P, Ma J, Pei D, Obert C, Cheng C, Geiger TL. Identification of errors introduced during high throughput sequencing of the $\mathrm{T}$ cell receptor repertoire. BMC Genomics. 2011; 12:106.

74. Miller NA, Farrow EG, Gibson M, Willig LK, Twist G, Yoo B, Marrs T, Corder S, Krivohlavek L, Walter A, Petrikin JE, Saunders CJ,Thiffault I, et al. A 26-hour system of highly sensitive whole genome sequencing for emergency management of genetic diseases. Genome Med. 2015; 7:100.

75. Petrikin JE, Willig LK, Smith LD, Kingsmore SF. Rapid whole genome sequencing and precision neonatology. Semin Perinatol. 2015; 39:623-31.

76. Bartley AN, Christ J, Fitzgibbons PL, Hamilton SR, Kakar S, Shah MA, Tang LH, Troxell ML; Members of the Cancer Biomarker Reporting Committee, College of American Pathologists. Template for reporting results of HER2 (ERBB2) biomarker testing of specimens from patients with adenocarcinoma of the stomach or esophagogastric junction. Arch Pathol Lab Med. 2015; 139:618-20.

77. Swerdlow SH, Campo E, Pileri SA, Harris NL, Stein H, Siebert R, Advani R, Ghielmini M, Salles GA, Zelenetz AD, Jaffe ES. The 2016 revision of the World Health Organization classification of lymphoid neoplasms. Blood. 2016; 127:2375-90.
78. Bowers DC, Kucejova B, Margraf L, Gargan L, Brugarolas J. mTORC1 activation in childhood ependymoma and response to sirolimus. J Neurooncol. 2011; 103:797-801.

79. Voss MH, Hakimi AA, Pham CG, Brannon AR, Chen YB, Cunha LF, Akin O, Liu H, Takeda S, Scott SN, Socci ND, Viale A, Schultz N, et al. Tumor genetic analyses of patients with metastatic renal cell carcinoma and extended benefit from mTOR inhibitor therapy. Clin Cancer Res. 2014; 20:1955-64.

80. Sawyer SL, Hartley T, Dyment DA, Beaulieu CL, Schwartzentruber J, Smith A, Bedford HM, Bernard G, Bernier FP, Brais B, Bulman DE, Warman Chardon J, Chitayat $\mathrm{D}$, et al. Utility of whole-exome sequencing for those near the end of the diagnostic odyssey: time to address gaps in care. Clin Genet. 2016; 89:275-84.

81. Rosell AM, Pena LD, Schoch K, Spillmann R, Sullivan J, Hooper SR, Jiang YH, Mathey-Andrews N, Goldstein DB, Shashi V. Not the end of the odyssey: Parental perceptions of whole exome sequencing (WES) in pediatric undiagnosed disorders. J Genet Couns. 2016 Feb 12 [Epub ahead of print].

82. Valencia CA, Husami A, Holle J, Johnson JA, Qian Y, Mathur A, Wei C, Indugula SR, Zou F, Meng H, Wang L, Li X, Fisher R, et al. Clinical Impact and Cost-Effectiveness of Whole Exome Sequencing as a Diagnostic Tool: A Pediatric Center's Experience. Front Pediatr. 2015; 3:67.

83. Parsons DW, Roy A, Yang Y, Wang T, Scollon S, Bergstrom K, Kerstein RA, Gutierrez S, Petersen AK, Bavle A, Lin FY, López-Terrada DH, Monzon FA, et al. Diagnostic yield of clinical tumor and germline wholeexome sequencing for children with solid tumors. JAMA Oncol. 2016 Jan 28 [Epub ahead of print]. doi: 10.1001/ jamaoncol.2015.5699.

84. Glade Bender J, Verma A, Schiffman JD. Translating genomic discoveries to the clinic in pediatric oncology. Curr Opin Pediatr. 2015; 27:34-43.

85. Scollon S, Bergstrom K, Kerstein RA, Wang T, Hilsenbeck SG, Ramamurthy U, Gibbs RA, Eng CM, Chintagumpala MM, Berg SL, McCullough LB, McGuire AL, Plon SE, et al. Obtaining informed consent for clinical tumor and germline exome sequencing of newly diagnosed childhood cancer patients. Genome Med. 2014; 6:69.

86. Hainsworth JD, Rubin MS, Spigel DR, Boccia RV, Raby S, Quinn R, Greco FA. Molecular gene expression profiling to predict the tissue of origin and direct site-specific therapy in patients with carcinoma of unknown primary site: a prospective trial of the Sarah Cannon research institute. J Clin Oncol. 2013; 31:217-23.

87. Greco FA. Molecular diagnosis of the tissue of origin in cancer of unknown primary site: useful in patient management. Curr Treat Options Oncol. 2013; 14:634-42.

88. Hainsworth JD, Greco FA. Gene expression profiling in patients with carcinoma of unknown primary site: from translational research to standard of care. Virchows Arch. 2014; 464:393-402. 
89. Xu Q, Chen J, Ni S, Tan C, Xu M, Dong L, Yuan L, Wang $\mathrm{Q}$, Du X. Pan-cancer transcriptome analysis reveals a gene expression signature for the identification of tumor tissue origin. Mod Pathol. 2016; 29:546-56.

90. Le Loarer F, Watson S, Pierron G, de Montpreville VT, Ballet S, Firmin N, Auguste A, Pissaloux D, Boyault S, Paindavoine S, Dechelotte PJ, Besse B, Vignaud JM, et al. SMARCA4 inactivation defines a group of undifferentiated thoracic malignancies transcriptionally related to BAFdeficient sarcomas. Nat Genet 2015; 47:1200-5.
91. Lebofsky R, Decraene C, Bernard V, Kamal M, Blin A, Leroy Q, Rio Frio T, Pierron G, Callens C, Bieche I, Saliou A, Madic J, Rouleau E, et al. Circulating tumor DNA as a non-invasive substitute to metastasis biopsy for tumor genotyping and personalized medicine in a prospective trial across all tumor types. Mol Oncol. 2015; 9:783-90. 